\section{A frequent nonsense mutation in exon 1 across certain HLA-A and HLA-B alleles in leukocytes of patients with acquired aplastic anemia}

\begin{abstract}
Hiroki Mizumaki, ${ }^{1}$ Kazuyoshi Hosomichi, ${ }^{2}$ Kohei Hosokawa, ${ }^{1}$ Takeshi Yoroidaka, ${ }^{1}$ Tatsuya Imi, ${ }^{1}$ Yoshitaka Zaimoku, ${ }^{1}$ Takamasa Katagiri, ${ }^{3}$ Mai Anh Thi Nguyen, ${ }^{1}$ Dung Cao Tran, ${ }^{1}$ Mahmoud Ibrahim Yousef Elbadry, ${ }^{1,4}$ Kazuhisa Chonabayashi, ${ }^{5}$ Yoshinori Yoshida, ${ }^{5}$ Hiroyuki Takamatsu, ${ }^{1}$ Tatsuhiko Ozawa, ${ }^{6}$ Fumihiro Azuma, ${ }^{7}$ Hiroyuki Kishi, ${ }^{6}$ Yoichi Fujii, ${ }^{8}$ Seishi Ogawa, ${ }^{8,9}$ Atsushi Tajima ${ }^{2}$ and Shinji Nakao ${ }^{1}$

${ }^{1}$ Department of Hematology, Kanazawa University, Kanazawa, Japan; ${ }^{2}$ Department of Bioinformatics and Genomics, Graduate School of Advanced Preventive Medical Sciences, Kanazawa University, Kanazawa, Japan; ${ }^{3}$ Clinical Laboratory Sciences, Kanazawa University Graduate School, Kanazawa, Japan; ${ }^{4}$ Department of Internal Medicine, Division of Hematology, Faculty of Medicine, Sohag University, Sohag, Egypt; ${ }^{5}$ Center for iPS Cell Research and Application, Kyoto University, Kyoto, Japan;

${ }^{6}$ Department of Immunology, University of Toyama, Toyama, Japan; ${ }^{7} \mathrm{HLA}$ Laboratory, Japanese Red Cross Kanto-Koshinetsu Block Blood Center, Kotoku, Japan; ${ }^{8}$ Department of Pathology and Tumor Biology, Graduate School of Medicine, Kyoto University, Kyoto, Japan and ${ }^{9}$ Department of Medicine, Center for Hematology and Regenerative Medicine (HERM), Karolinska Institute, Stockholm, Sweden
\end{abstract}

\section{ABSTRACT}

L eukocytes that lack expression of HLA alleles are frequently detected in patients with acquired aplastic anemia (AA) who respond to immunosuppressive therapy, although the exact mechanisms underlying the HLA loss and HLA allele repertoire likely to acquire loss-of-function mutations are unknown. We identified a common nonsense mutation at codon 19 (c.19C>T, p.R7X) in exon 1 (Exon1 $1^{\text {mut }}$ ) of different HLA-A and -B alleles in HLA-lacking granulocytes from AA patients. A droplet digital polymerase chain reaction assay capable of detecting as few as $0.07 \%$ Exon $1^{\text {mut }}$ HLA alleles in total DNA revealed that the mutation was present in $29 \%(101 / 353)$ of AA patients, with a median allele frequency of $0.42 \%$ (range, $0.071 \%$ to $21.3 \%$ ). Exon $1^{\text {mut }}$ occurred in only 12 different HLA-A $(\mathrm{n}=4)$ and HLA-B $(\mathrm{n}=8)$ alleles, including $B^{*} 40: 02 \quad(\mathrm{n}=31)$ and $A^{*} 02: 06$ $(\mathrm{n}=15)$, which correspond to four HLA class I supertypes (A02, A03, B07, and B44). The percentages of patients who possessed at least one of these 12 HLA alleles were significantly higher in the 353 AA patients $(92 \%$, $P<0.001)$ and in 83 AA patients with copy number neutral loss of heterozygosity in chromosome $6 p(100 \%, P<0.001)$ than the percentage $(81 \%)$ in 18,604 Japanese healthy individuals. Eighty-two percent (37/45) of AA patients with Exon1 $1^{\text {mut }}$ responded to immunosuppressive therapy. Small populations of leukocytes that lack particular HLA-A or B alleles due to Exon $1^{\text {mut }}$ are common in AA patients. The detection of Exon $1^{\text {mut }}$ using a droplet digital polymerase chain reaction assay without the need for HLA typing may serve as a powerful tool for diagnosing the immune pathophysiology of patients with bone marrow failure.

\section{Introduction}

Acquired aplastic anemia (AA) is a rare condition characterized by pancytopenia and bone marrow hypoplasia resulting from immune-mediated suppression of hematopoietic stem progenitor cells (HSPC). ${ }^{1}$ Among several different immune mechanisms, cytotoxic T lymphocytes that recognize auto-antigens presented by HSPC are thought to play a critical role in the development of $A A,{ }^{2 \cdot 7}$ based on the finding that leukocytes that lack particular HLA-A or HLA-B alleles (HLA-allele-
Ferrata Storti Foundation

Haematologica 2021

Volume 106(6):1581-1590

\section{Correspondence:}

SHINJ NAKAO

snaka08205@staff.kanazawa-u.ac.jp

Received: February 16, 2020.

Accepted: May 14, 2020.

Pre-published: May 21, 2020.

https://doi.org/10.3324/haematol.2020.247809

(C)2021 Ferrata Storti Foundation

Material published in Haematologica is covered by copyright. All rights are reserved to the Ferrata Storti Foundation. Use of published material is allowed under the following terms and conditions:

https://creativecommons.org/licenses/by-nc/4.0/legalcode. Copies of published material are allowed for personal or internal use. Sharing published material for non-commercial purposes is subject to the following conditions:

https://creativecommons.org/licenses/by-nc/4.0/legalcode, sect. 3. Reproducing and sharing published material for commercial purposes is not allowed without permission in writing from the publisher. 
lacking leukocytes: HLA-LL) are often detected in the peripheral blood of AA patients. ${ }^{8,9}$ The presence of HLALL represents compelling evidence to support the involvement of cytotoxic T lymphocytes specific to HSPC in the development of bone marrow failure, and the detection of these leukocytes would be useful for diagnosing immune pathophysiology in patients with AA and other types of bone marrow failure, including low-risk myelodysplastic syndrome. However, assays for detecting HLA-LL, such as flow cytometry using monoclonal antibodies specific to HLA-A or HLA-B alleles and single nucleotide polymorphism (SNP) arrays, have not been popularized because of the need for HLA typing and low frequencies of copy number neutral loss of heterozygosity of the short arm of chromosome $6(6 \mathrm{pLOH}))^{10,11}$

$6 \mathrm{pLOH}$ was considered the most common way for HSPC to lose HLA alleles. ${ }^{10-15}$ We recently reported that, using targeted deep sequencing with a next-generation sequencer, somatic loss-of-function mutations of HLA$B^{*} 40: 02$ were frequently detected in granulocytes of AA patients possessing $H L A-B^{*} 40: 02$. These results strongly suggested that antigen presentation by HSPC via HLAB4002 plays a critical role in the pathogenesis of AA. Loss-of-function mutations in HLA class I alleles other than HLA-B*40:02 were also detected in patients with AA. Babushok et al. identified mutations in several HLA class I alleles in leukocytes of AA patients, including HLA$A^{*} 33: 03, A^{*} 68: 01$ and HLA-B*14:02. ${ }^{14}$ We recently analyzed leukocytes of AA patients with $6 \mathrm{pLOH}$ and detected somatic loss-of-function mutations in $H L A-A^{*} 02: 06$ and $B^{*}$ 54:01 ${ }^{16,17}$ However, HLA class I alleles responsible for autoantigen presentation in AA patients without HLA$B^{*} 40: 02$, who account for approximately $80 \%$ of all AA patients, are largely unknown due to the limited number of AA patients who have been studied for loss-of-function mutations in HLA class I alleles.

To identify HLA class I alleles other than HLA-B*40:02 that are involved in the autoantigen presentation of $A A$, we performed targeted next-generation sequencing in AA patients with HLA-LL who had HLA class I alleles other than $H L A-B^{*} 40: 02$. During the course of the mutation analysis, we identified a nonsense mutation at codon 19 (c.19C>T, p.R7X) in exon 1 (Exon $\left.1^{m u}\right)$ of some HLA-A or HLA-B alleles. Surprisingly, Exon $1^{\text {mut }}$ was shared by different HLA-A or HLA-B alleles and was prevalent in AA patients although their variant allelic frequencies (VAF) were very low. A sensitive assay that can detect Exon $1^{\text {mut }}$ could help to identify HLA-A or HLA-B alleles that are responsible for autoantigen presentation and provide insight into the immune pathophysiology of bone marrow failure.

Against this backdrop, we developed a highly sensitive droplet digital PCR (ddPCR) assay for detecting Exon $1^{\text {mut }}$, and determined the prevalence of Exon $1^{\text {mut }}$ and HLA alleles likely to acquire this mutation in AA patients.

\section{Methods}

Detailed information on the materials and methods are provided in the Online Supplementary Data.

\section{Patients}

Twenty Japanese AA patients with HLA-LL who did not have an $H L A-B^{*} 40: 02$ allele were analyzed for the presence of loss-offunction mutations in HLA alleles. We studied a total of 353
Table 1. Baseline characteristics of the patients with aplastic anemia.

\begin{tabular}{lc}
\hline Characteristics & N. of patients \\
Total & 353 \\
Age in years, median (range) & $63(11-93)$ \\
\hline Sex, male/female & $167 / 186$ \\
Severity & \\
Non-severe AA & 202 \\
Severe/very severe AA & 151 \\
\hline Patients with increased GPI- granulocytes, n (\%) & $245(69.4)$ \\
None (<0.003\%) & 108 \\
$0.003-1.0 \%$ & 177 \\
$>1.0 \%$ & 68 \\
IST prior to sampling, n (\%) & $61(17.2)$ \\
CsA \pm TPO-RA & 31 \\
rATG+CsA \pm TPO-RA & 30 \\
\hline
\end{tabular}

GPI-: glycosylphosphatidylinositol-anchored proteins deficient; AA: aplastic anemia; IST: immunosuppressive therapy; CsA: cyclosporine; TPO-RA: thrombopoietin receptor agonist; ATG: antithymocyte globulin.

Japanese AA patients, including the 20 patients who were further analyzed for the prevalence and clinical significance of Exon $1^{\text {mut }}$ in AA between 2010 and 2018 (Table 1). A schematic of the experiments is provided in Online Supplementary Figure S1. All patients were genotyped for HLA-A, HLA-B, HLA-C, and HLA-DRB1 alleles using the PCR sequence-specific oligonucleotide method. All patients provided consent to participation in this study, which was conducted in accordance with the Declaration of Helsinki and approved by the ethics committee of the Kanazawa University Institute of Medical, Pharmaceutical, and Health Sciences.

\section{Detection of glycosylphosphatidylinositol-deficient cells and cells with $6 p$ loss of heterozygosity}

Glycosylphosphatidylinositol-anchored protein-deficient (GPI-) cells were detected using high sensitivity flow cytometry, as previously described..$^{18} 6 \mathrm{pLOH}$ was assessed using a SNP array-based method with GeneChip 500K arrays (Affymetrix, Japan) or a ddPCR assay with a OX200 AutoDG Droplet Digital PCR System (Bio-Rad, CA, USA), as previously described..$^{9,10}$

\section{Deep sequencing of HLA class I genes}

From peripheral blood samples of the 20 patients with HLA-LL, which were stained with anti-HLA-allele-specific and lineage-specific monoclonal antibodies, paired fractions of granulocytes and $\mathrm{CD}^{+} \mathrm{T}$ cells were sorted and were subjected to DNA extraction (Online Supplementary Figure S2). The monoclonal antibodies used in this study are summarized in Online Supplementary Table S1. Nucleotide sequences of HLA-A and HLA-B genes in sorted granulocytes of patients with HLA-LL were determined using a nextgeneration sequencer (Miseq; Illumina, CA, USA).

\section{Digital droplet polymerase chain reaction assay for detecting Exon $1^{\text {mut }}$}

We developed a sensitive ddPCR assay for precise detection of Exon $1^{\text {mut }}$ in the peripheral blood of AA patients using the OX200 ddPCR system. Briefly, we designed two different sets of primer pairs complementary to the consensus sequences of HLA-A and HLA-B alleles, and locked nucleic acid-based probes complementary to wild-type and mutant-specific sequences (Online Supplementary Table S2). Detailed protocols for ddPCR are provided in the Online Supplementary Methods.

\section{Determination of HLA alleles that acquired Exon $1^{\text {mut }}$}

HLA alleles that acquired Exon $1^{\text {mut }}$ were determined by deep sequencing with the next-generation sequencer, or deduced from 
alleles contained in the lost haplotype due to $6 \mathrm{pLOH}$ that was accompanied by Exon $1^{\text {mut }}$ (Online Supplementary Figure S3). The low VAF of Exon $1^{\text {mut }}$ (VAF $<1 \%$ ) was confirmed by deep sequencing with unique molecular identifiers $\left(x G e n^{\circledast}\right.$ Dual Index UMI Adapters: Integrated DNA Technologies, IA, USA). ${ }^{19}$ The correlation between Exon $1^{\text {mur }}$ VAF determined by deep sequencing with unique molecular identifiers and those determined by the ddPCR assay was examined using 24 different samples (Online Supplementary Figure S4). HLA class I alleles acquiring Exon $1^{\text {mut }}$ were determined using the nearest allele-specific SNP. Details on deep sequencing with unique molecular identifiers are provided in the Online Supplementary Methods.

\section{Statistical analysis}

Comparisons were performed using the Fisher exact test for categorical variables and Mann-Whitney $U$ test for continuous variables with a two-tailed significance level of 0.05 . Statistical analyses were performed using the EZR software program..$^{20}$ Graphs were generated using GraphPad PRISM7.0 (GraphPad Software Inc, CA, USA).

A

Chr6:29,910,349

UPN 262

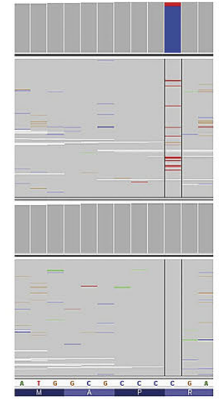
A2(-) Granulocytes
p.R7*(c.19C $>$ T)
C: 1910
T: 156

\section{T cells (germline control)}

C: 1850

T: 0
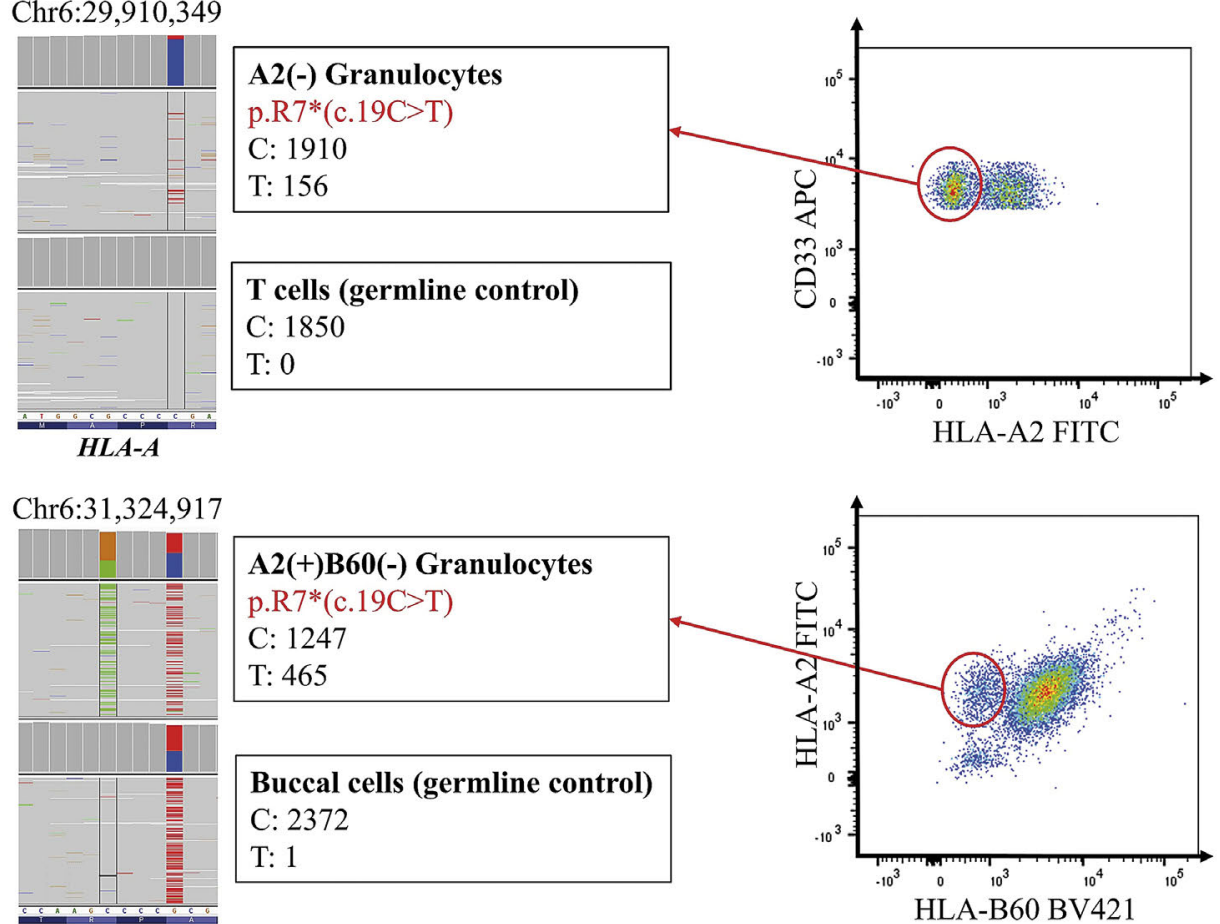

UPN 211

HLA-B
A2(+)B60(-) Granulocytes
p.R $7^{*}(\mathrm{c} .19 \mathrm{C}>\mathrm{T})$
C: 1247
T: 465

Buccal cells (germline control)

C: 2372

T: 1

HLA-B60 BV421

B
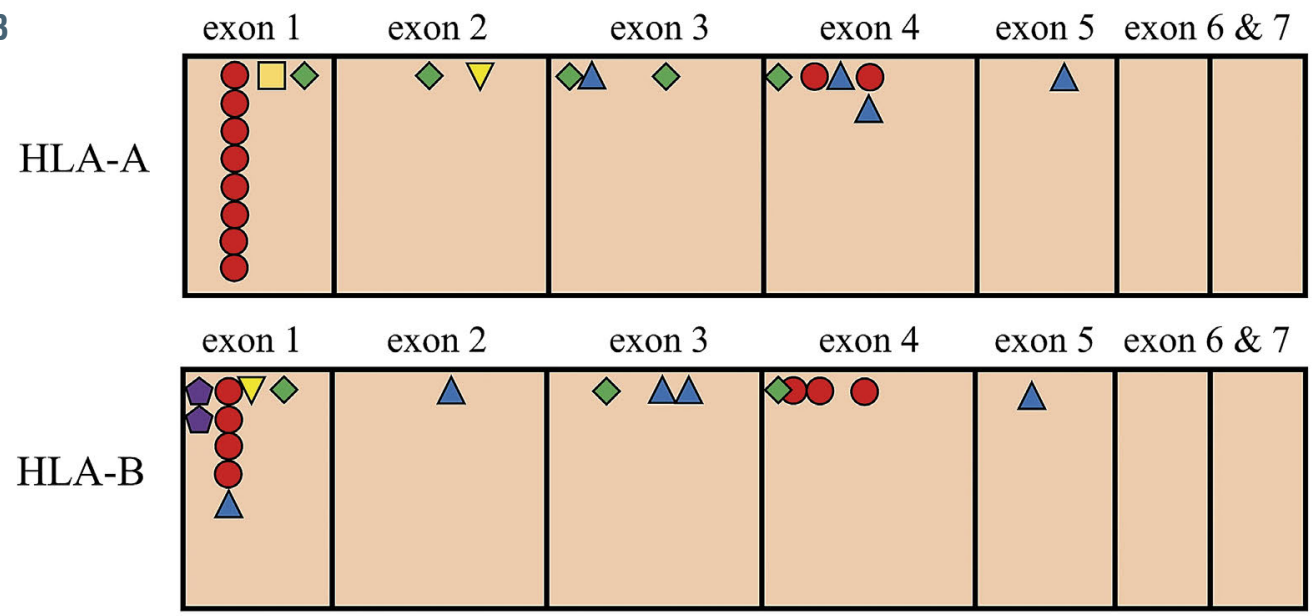

Nonsense mutation \& $\diamond$ Frameshift insertion stop gain mutation

Start loss $\triangle$ Frameshift deletion $\nabla$ Non frameshift insertion

Missense mutation

Figure 1. Identification of Exon $1^{\text {mut }}$ in patients with aplastic anemia. (A) Exon $1^{\text {mut }}\left[\mathrm{p} . \mathrm{R} 7{ }^{*}(\mathrm{c} .19 \mathrm{C}>\mathrm{T})\right]$ was detected by targeted deep sequencing of sorted HLA-A2 ${ }^{-}$granulocytes (UPN 262) and HLA-A2 ${ }^{+} B 60^{-}$granulocytes (UPN 211) in two patients with aplastic anemia. Sequencing results of sorted HLA-allele lacking leukocytes from these two patients and germline controls and flow cytometry results of granulocytes are shown. (B) Loss-of-function mutations detected in 14 patients by targeted deep sequencing. Exon $1^{\text {mut }}$ was detected in HLA-A alleles of eight patients and HLA-B alleles of four patients. UPN: unique patient number. 


\section{Results}

Identification of Exon1 ${ }^{\text {mut }}$ in different HLA-A and HLA-B alleles in HLA-lacking leukocytes from patients with aplastic anemia

To identify HLA class I alleles other than $H L A-B^{*} 40: 02$ that are critically involved in autoantigen presentation in AA, we sequenced HLA-A and HLA-B alleles of sorted granulocytes from 20 patients with HLA-LL not possessing $H L A-B^{*} 40: 02$. The clinical characteristics of these 20 patients are shown in Online Supplementary Table S3. HLA$\mathrm{A}^{-}$granulocytes or HLA- $\mathrm{A}^{+} \mathrm{B}^{-}$granulocytes, accounting for $2.4-99.8 \%$ of all granulocytes, were detected in these patients (Online Supplementary Figure S5, Online Supplementary Table S3). Median read depths of the HLAA and HLA-B alleles were 925 and 1,012 for targeted deep sequencing and 43,013 and 35,267 for amplicon sequencing, respectively. Of the $20 \mathrm{AA}$ patients assessed, six had $6 \mathrm{pLOH}$ alone, ten had various loss-of-function mutations in addition to $6 \mathrm{pLOH}$, and four had only somatic loss-offunction mutations in HLA-A. Three (UPN 210, 335, and 348 ) of the 14 patients with loss-of-function mutations had the mutations in HLA-B of sorted HLA- $\mathrm{A}^{+}$granulo- cytes. Of note, 12 of 14 patients with loss-of-function mutations had Exon $1^{\text {mut }}$ in HLA-A $\left(A^{*} 02: 06, \mathrm{n}=7 ; A^{*} 31: 01\right.$, $\mathrm{n}=1)$ and HLA-B $\left(B^{*} 13: 01, \mathrm{n}=1 ; B^{*} 40: 01, \mathrm{n}=2 ;\right.$ and $B^{*} 54: 01$, $\mathrm{n}=1$ ). The other two patients (UPN 335 and UPN 210) had different loss-of-function mutations from Exon $1^{\text {mut }}$ in HLA$B^{*} 40: 03$ and $H L A-B^{*} 54: 01$, respectively. Interestingly, a frameshift mutation of $H L A-B^{*} 54: 01$ also occurred at codon 19 (c.19delC, p.R7Efs) in exon 1 (Figure 1A and B, Online Supplementary Table S4).

\section{Exon $1^{\text {mut }}$ detection using a sensitive droplet digital polymerase chain reaction assay}

To detect Exon $1^{\text {mut }}$ with high sensitivity and specificity, we established a ddPCR assay that allows for precise measurement of mutant allele frequency without the need for HLA typing. Tested samples containing a fixed amount of wild-type DNA and serial dilutions of Exon $1^{\text {mut }}$ template DNA revealed a detection limit of $0.07 \%$ for both HLA-A and HLA-B (Online Supplementary Figure S6). The ddPCR assay yielded $0 \%$ to $0.042 \%$ (median, $0.009 \%$ ) positive dots in peripheral blood of 24 healthy individuals, validating the cut-off value of $0.07 \%$. The ddPCR assay was able to detect Exon $1^{\text {mut }}$, which had an allelic frequency of $<1.0 \%$
A

UPN 299

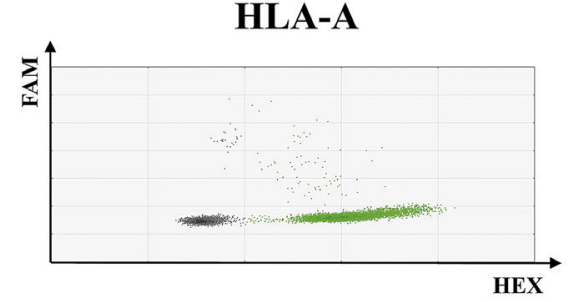

VAF $=0.92 \%$ (Positive)

HLA-A

UPN 211

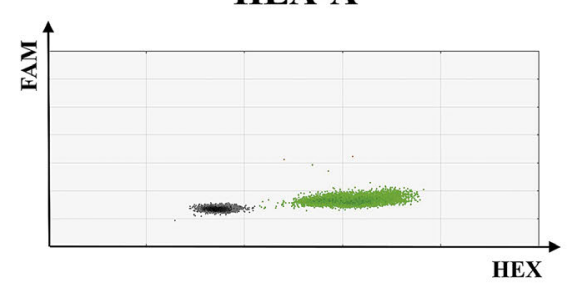

$\mathrm{VAF}=\mathbf{0 . 0 1 6 \%}$ (Negative)

B

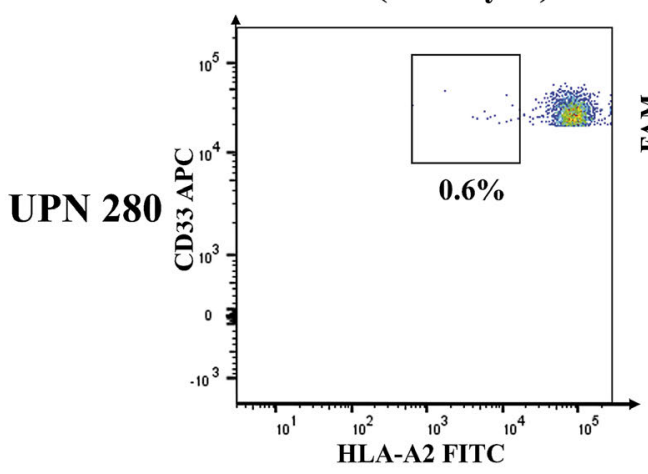

HLA-B

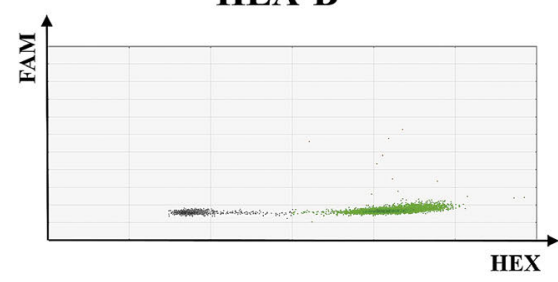

$\mathrm{VAF}=\mathbf{0 . 0 4 5} \%$ (Negative)

HLA-B

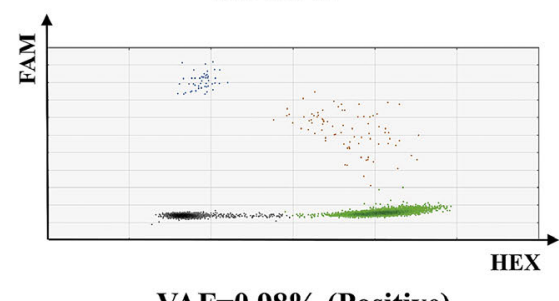

VAF $=0.98 \%$ (Positive $)$

ddPCR (Whole blood)

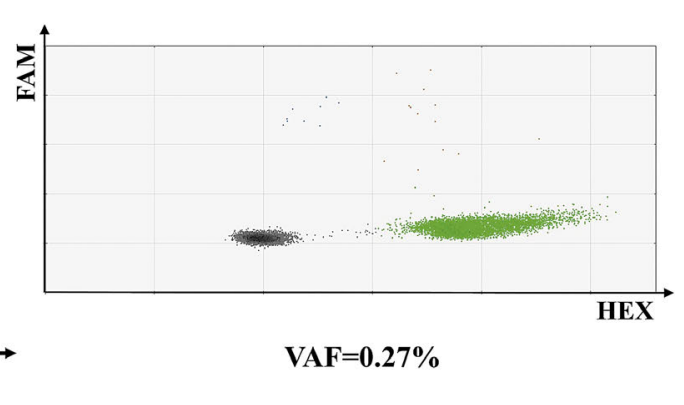

Figure 2. Detection of Exon $1^{\text {mut }}$ using the droplet digital polymerase chain reaction assay. (A) Representative droplet digital polymerase chain reaction (ddPCR) plots of Exon $1^{\text {mut }}$ in two patients with aplastic anemia. The ddPCR assay detected $0.92 \%$ Exon $1^{\text {mut }}$ DNA in $H L A$ $A * 02: 06$ of UPN 299 and $0.98 \%$ Exon $1^{\text {mut }}$ DNA in HLA$B \star 40: 01$ of UPN 211. (B) A minor population of HLAallele-lacking leukocytes in UPN 280 detected by flow cytometry and the ddPCR assay. The ddPCR assay detected $0.27 \%$ Exon $^{\text {mut }}$ in whole blood where granulocytes and monocyte with Exon $1^{\text {mut }}$ were diluted with lymphocytes without Exon $1^{\text {mut }}$. The percentage of Exon $1^{\text {mut }}$-positive cells was consistent with the percentage of HLA-A2 monocytes $(0.6 \%)$ detected by flow cytometry. UPN: unique patient number; VAF: variant allele frequency; FCM flow cytometry. 
(Figure 2A), clearly showing the presence of HLA-LL in patients for whom flow cytometry analysis of monocytes using anti-HLA-A2 antibodies produced unequivocal results regarding the presence of HLA-A2-lacking monocytes (Figure 2B).

\section{Prevalence of Exon $1^{\text {mut }}$ in patients with aplastic anemia}

Using two different ddPCR mixtures for HLA-A and HLA-B, the presence of Exon $1^{\text {mut }}$ was evaluated in all of the 353 patients. Exon $1^{\text {mut }}$ was detected in 101 (28.6\%) of the 353 patients, with the median frequency of $0.42 \%$ (range, $0.071 \%$ to $21.3 \%$ ). The prevalence of Exon $1^{\text {mut }}$ was similar in HLA-A and HLA-B alleles in both treatment-naive patients $(n=291)$ and treated patients $(n=62)$. Among the AA patients with Exon1 $1^{\text {mut }}$, those who had been treated had a higher median frequency of Exon $1^{\text {mut }}$ than those who were untreated $(0.96 \%$ vs. $0.33 \%, P=0.0079)$ (Figure $3 \mathrm{~A})$. Figure $3 \mathrm{~B}$ shows the relationships between the presence of cells with Exon1 $1^{m u t}, 6 \mathrm{pLOH}$ and a paroxysmal nocturnal hemoglobinuria (PNH) phenotype in the patients. Fifty-six $(55.4 \%)$ and $67(66.3 \%)$ of the 101 patients with Exon $1^{\text {mut }}$ had $6 \mathrm{pLOH}$ and $\mathrm{PNH}$ phenotype cells, respectively. Ten $(2.8 \%)$ of the 353 patients had Exon $1^{\text {mut }}$ alone. The frequency of Exon1 $1^{\text {mut }}$ was much lower than that of $6 \mathrm{pLOH}$ in 36 patients possessing both clones $(P<0.001)$ (Figure 3C).
Long-term persistence of Exon $1^{\text {mut }}$-positive cells

Serial blood samples were available for longitudinal analyses of Exon $1^{\text {mut }}$ in 13 patients who responded to immunosuppressive therapy (cyclosporine [CsA] alone in 6 and rabbit antithymocyte globulin [rATG] + CsA in 5) or anabolic steroids $(n=2)$. Exon $1^{\text {mut }}$ was persistently detected for 14-86 months in nine patients, including one patient (UPN 299) who had been off treatment for 7 years, suggesting that Exon ${ }^{\text {mut }}$-positive leukocytes are derived from long-lasting HSPC (Figure 4A). The VAF of Exon $1^{m u}$ increased in two (15\%, UPN 333 and UPN 339), remained stable in four $(31 \%)$, and decreased in three $(23 \%)$ patients. Exon $1^{\text {mut }}$ became undetectable at 7-33 months after the first detection of Exon $1^{\text {mut }}$ in the other four patients, all of whom were being treated with CsA. Figure $4 \mathrm{~B}$ shows a gradual decline of the Exon $1^{\text {mut }}$ frequency over 3 years in one patient (UPN 213).

\section{HLA-A and HLA-B alleles that acquire Exon $1^{\text {mut }}$}

Among the 101 patients with Exon1 ${ }^{\text {mut }}$. HLA alleles that acquired Exon $1^{\text {mut }}$ could be determined by targeted deep sequencing with $(n=21)$ or without $(n=37)$ unique molecular identifiers, or deduced from alleles contained in the lost haplotype due to $6 \mathrm{pLOH}$ that was accompanied by Exon1 $^{\text {mut }}(\mathrm{n}=10)$ (Online Supplementary Figure S2). In the
A

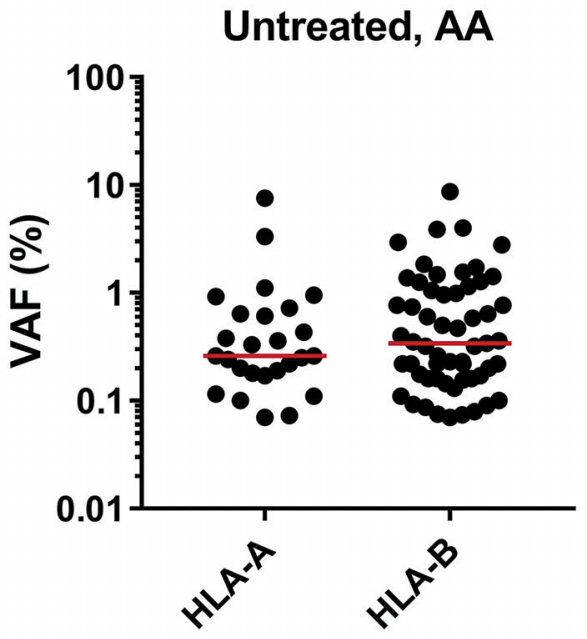

B

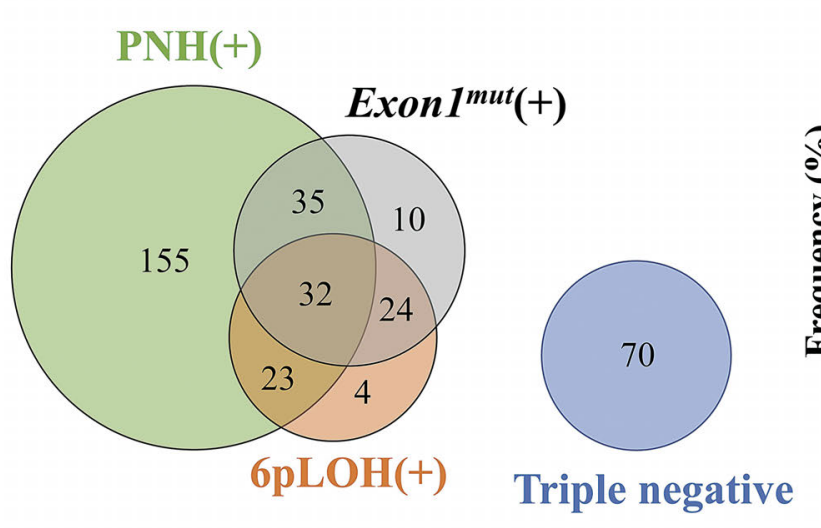

Treated, AA

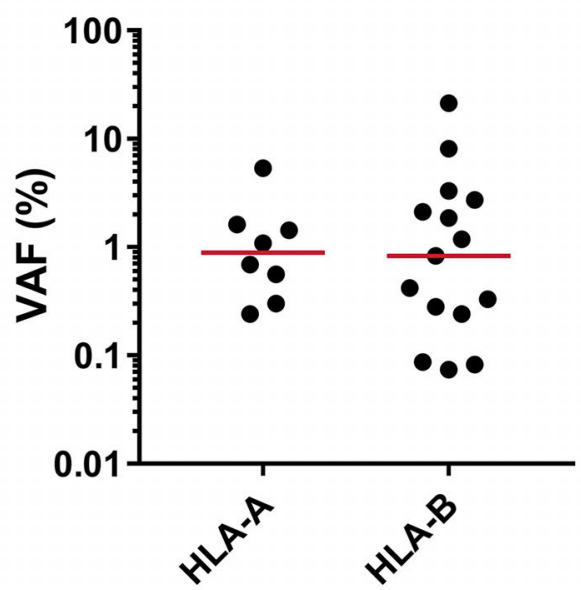

C

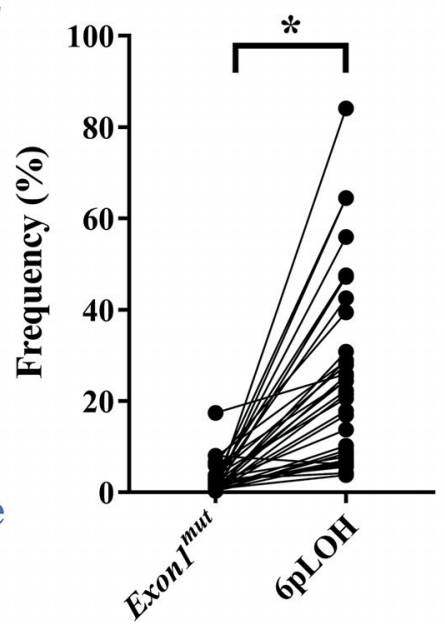

Figure 3. Prevalence and clone size of Exon $1^{\text {mut }}$ in patients with aplastic anemia. (A) Mutant allele frequency of Exon $1^{\text {mut }}$ in 291 and 62 Exon $1^{\text {mut }}$ positive untreated and treated patients with aplastic anemia, respectively. Red bars indicate median allele frequencies of Exon $1^{\text {mut }}$. (B) The prevalence of Exon $1^{\text {mut }}$ and its relationship with paroxysmal nocturnal hemoglobinuria phenotype (PNH) and copy number neutral loss of heterozygosity of the short arm of chromosome $6(6 \mathrm{pLOH})$. Exon $1^{\text {mut }}$-positive patients accounted for $58 \%$ of $6 \mathrm{pLOH}^{+} \mathrm{PNH}^{+}$patients and for $67 \%$ of $6 \mathrm{pLOH}^{+}$patients. (C) Frequency of Exon $1^{\text {mut }}$ and $6 \mathrm{pLOH}$ in individual patients who were positive for both mutant clones. The frequencies of both clones were determined by droplet digital polymerase chain reaction analysis. $* P<0.001$. VAF: variant allele frequency; $A A$ : aplastic anemia; UPN: unique patient number. 
other 33 patients with Exon1 ${ }^{\text {mut }}$, HLA-A or HLA-B alleles that acquired Exon $1^{\text {mut }}$ could not be determined or deduced due to very low VAF $(<0.2 \%)$, the absence of allele-specific SNP near Exon $1^{\text {mut }}$ in HLA-A or HLA-B alleles that are useful for identify missing HLA alleles, or the absence of coexisting $6 \mathrm{pLOH}$. For the 68 patients in whom HLA alleles that acquired Exon $1^{\text {mut }}$ could be determined, the following 12 alleles were identified: $A^{*} 02: 01(\mathrm{n}=2), A^{*} 02: 06$ $(\mathrm{n}=15), A^{*} 02: 07 \quad(\mathrm{n}=1), A^{*} 31: 01 \quad(\mathrm{n}=3), B^{*} 13: 01 \quad(\mathrm{n}=2)$, $B^{*} 40: 01 \quad(\mathrm{n}=3), B^{*} 40: 02(\mathrm{n}=31), B^{*} 40: 03 \quad(\mathrm{n}=1), B^{*} 44: 03$ $(\mathrm{n}=1), B^{*} 54: 01(\mathrm{n}=6), B^{*} 55: 02(\mathrm{n}=2)$, and $B^{*} 56: 01(\mathrm{n}=1)$
(Figure 5A). HLA class I supertypes of these alleles, which are defined by similarities in the antigen-presenting amino-acid motif of HLA alleles, were confined to only four supertypes: A02, A03, B07, and B44, except for HLA$B^{*}$ 13:01 that does not belong to any of the 14 supertypes. ${ }^{21}$

When comparing the frequency of these 12 alleles between a healthy control population and our study cohort, $81 \%$ of 18,604 healthy Japanese individuals possessed at least one of the 12 alleles, while the prevalence was $92 \%$ in the 353 patients with $\mathrm{AA}(P<0.001)$ and $100 \%$ in the 83 patients with $6 \mathrm{pLOH}(P<0.001)$ (Figure $5 \mathrm{~B})$, sug-

A

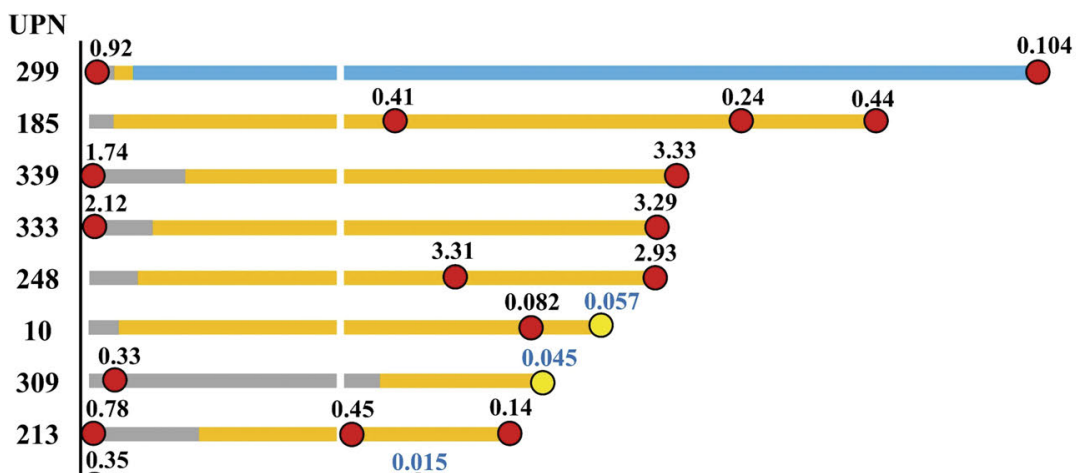

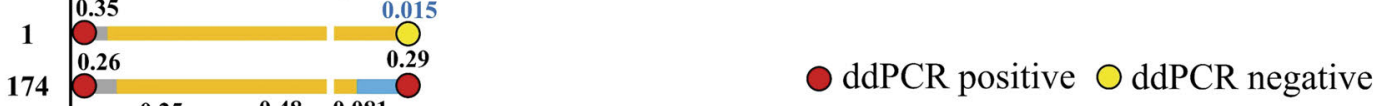

$280 \quad \begin{array}{ccccc}0.25 & 0.48 & 0.081 & O & \text { On treatment, no response }\end{array}$

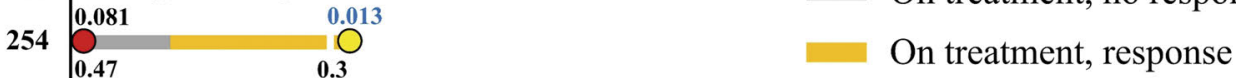

263

$0.47 \quad 0.3$

Off treatment

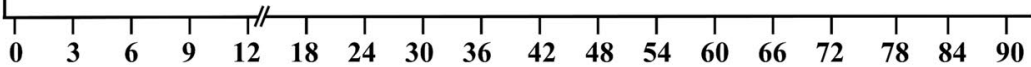

Month after treatment

B

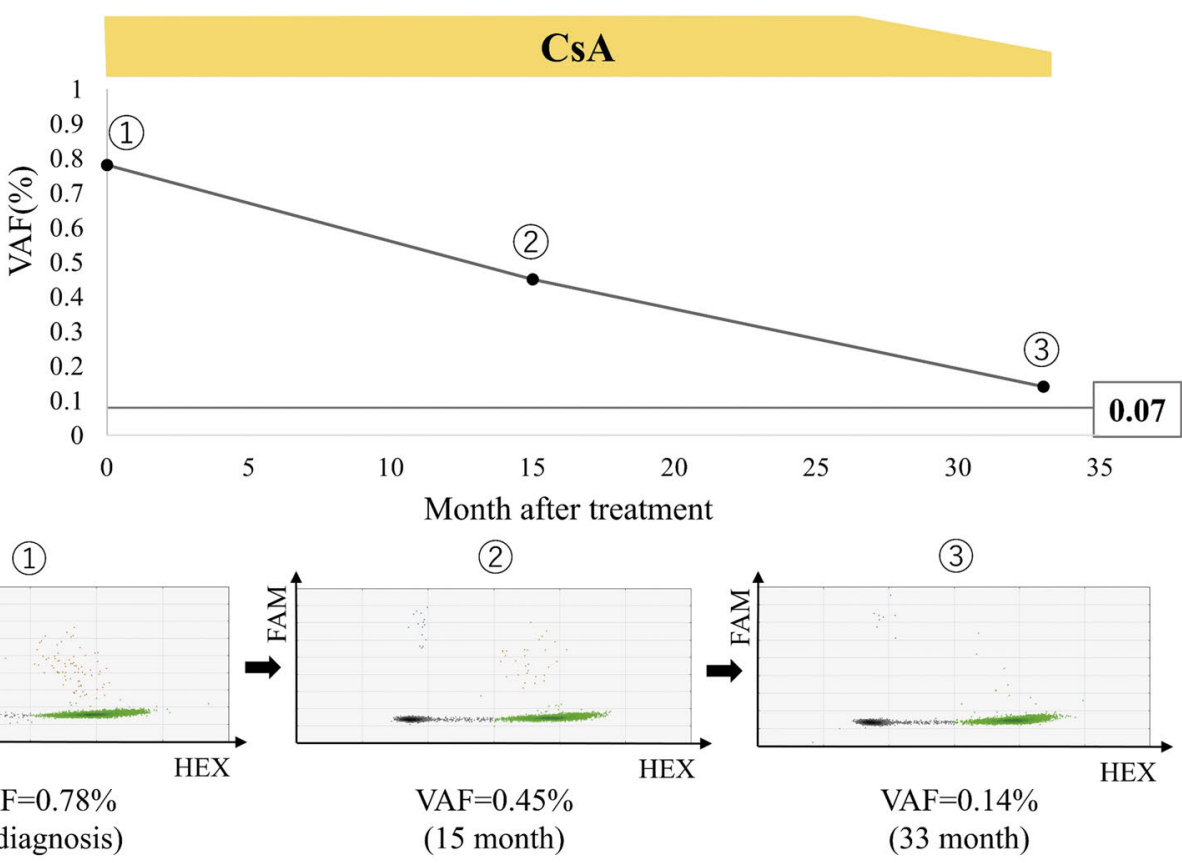

Figure 4. Temporal changes in allelic frequency of Exon $1^{\text {mut. }}$. (A) Allelic frequencies of Exon $1^{\text {mut }}$ determined at different time points in 13 patients and their disease status. (B) Representative scattergrams from UPN 213 showing a gradual decline in Exon $1^{\text {mut }}$ frequency over the course of 3 years. UPN: unique patient number; ddPCR: droplet digital polymerase chain reaction; CsA: cyclosporine A; VAF: variant allele frequency. 
gesting the involvement of these alleles in the development of AA.

\section{Loss of HLA-B expression from Exon $1^{\text {mut }}$-positive leukocytes}

Although Exon $1^{\text {mut }}$ in leukocytes is expected to result in lack of the corresponding HLA allele, the phenotype of these leukocytes is difficult to examine since the VAF of Exon $1^{\text {mut }}$ is very low. We previously established six induced pluripotent stem (iPS) cell clones from peripheral blood monocytes of an AA patient (UPN 333) whose monocytes included approximately $60 \%$ HLA-A24 $4^{+} \mathrm{Bw} 6^{-}$cells (Figure $6 \mathrm{~A}) .{ }^{17}$ Deep sequencing revealed the presence of Exon $1^{\text {mut }}$ in sorted HLA-A24 Bw6 $6^{-}$cells and also in one (clone C1) of the six iPS cell clones. When a wild-type iPS clone (clone E1) and clone $\mathrm{C} 1$ were induced to differentiate into $\mathrm{CD} 34^{+}$ cells, all clone E1-derived CD34+ cells expressed HLA-Bw6 (B5401), while all clone C1-derived CD34+ cells lacked HLA-Bw6 (Figure 6B). The ddPCR assay using DNA from wild-type and Exon1 $1^{\text {mut }}$-positive iPS cell-derived CD34 ${ }^{+}$ cells revealed that the VAF of Exon $1^{\text {mut }}$ were $0.041 \%$ and $49 \%$, respectively, as expected (Figure 6C).

\section{Clinical characteristics of aplastic anemia patients with Exon1 $1^{\text {mut }}$}

Of the 291 patients whose peripheral blood samples were examined for Exon $1^{\text {mut }}$ and $\mathrm{GPI}^{-}$cells before treatment, 151 were evaluable for response to immunosuppressive therapy (CsA alone, $n=68$; CsA+rATG, $n=83$ ). The other 140 patients were excluded from the analysis of the relationship between the response to immunosuppressive therapy and the presence of Exon1 $1^{\text {mut }}$ or $\mathrm{GPI}^{-}$cells because no data on the response to immunosuppressive therapy were available in 84 , and the remaining 56 received no treatment $(n=25)$ or treatments other than immunosuppressive therapy $(n=31)$, such as anabolic steroids and thrombopoietin receptor agonists, and allogeneic stem cell transplantation. An increase in $\mathrm{GPI}^{-}$cells was noted in $76 \%(34 / 45)$ of patients with Exon $1^{\text {mut }}$ and in $76 \%(81 / 106)$ without Exon $1^{\text {mut }}(P=1.0)$. In terms of response to immunosuppressive therapy, $82 \%(37 / 45)$ of patients with Exon1 $1^{\text {mut }}$ responded to CsA $(\mathrm{n}=14)$ or CsA+rATG $(n=23)$, while $75 \%(79 / 106)$ of those without Exon1 $1^{\text {mut }}$ responded to CsA $(\mathrm{n}=35)$ or CsA+rATG $(\mathrm{n}=44)$ $(\mathrm{P}=0.40)$. The response rate to immunosuppressive thera-

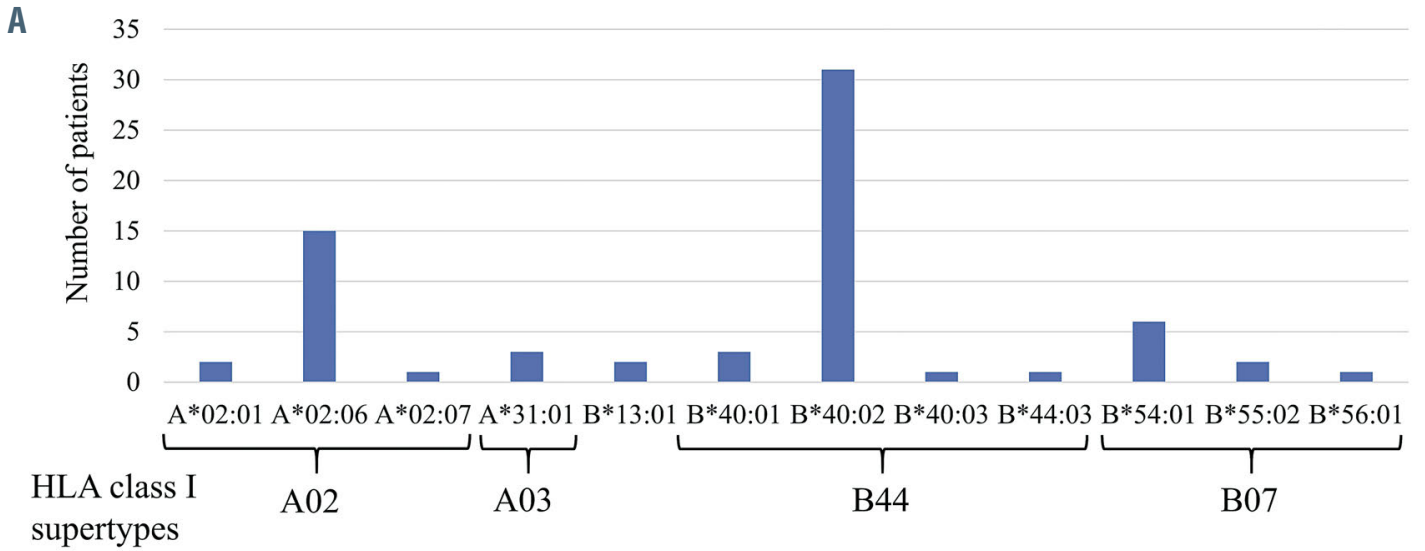

B
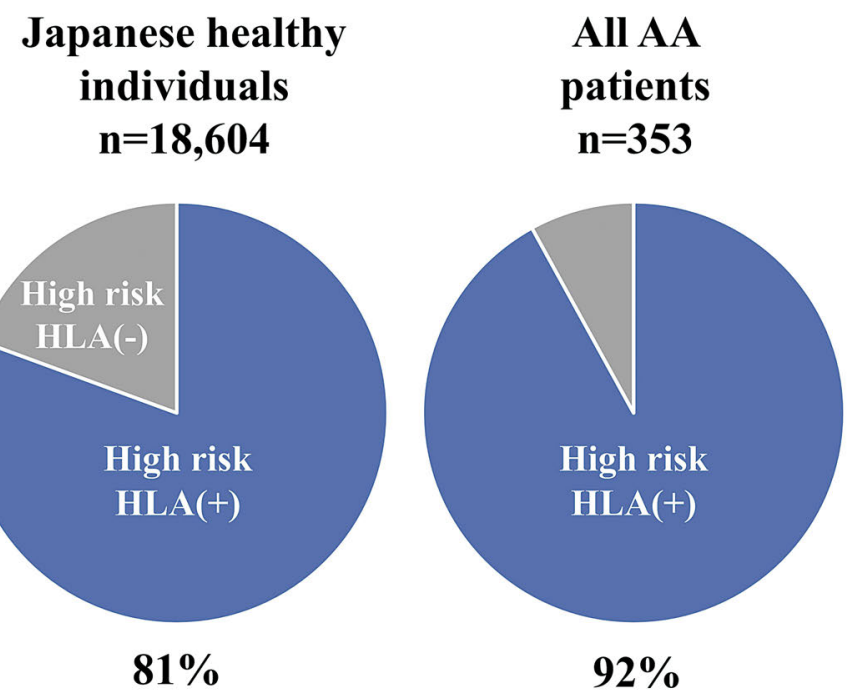
$6 \mathrm{pLOH}(+)$ AA patients $\mathbf{n}=\mathbf{8 3}$

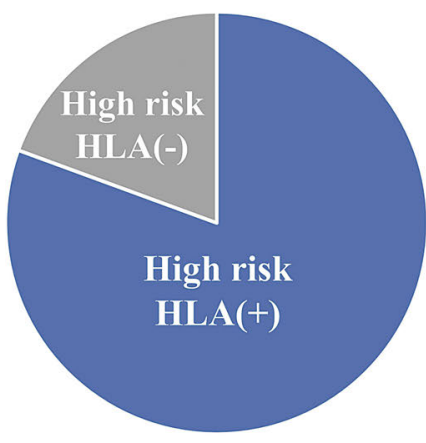

$81 \%$

$92 \%$

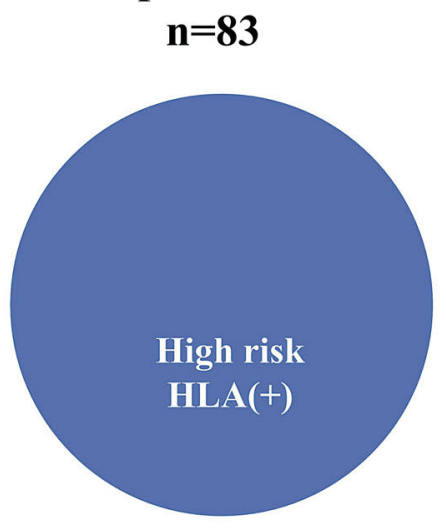

$100 \%$

Figure 5. HLA alleles that acquired Exon $1^{m u t}$. (A) The number of cases that acquired Exon $1^{\text {mut }}$ in the corresponding HLA alleles are shown. HLA numbers shown below the bar graph denote the HLA class I supertypes to which each allele belongs. (B) Proportions that the 12 HLA alleles account for in the different populations. AA: aplastic anemia; $6 \mathrm{pLOH}$ : copy number neutral loss of heterozygosity of the short arm of chromosome 6 . 
py in patients with Exon $1^{\text {mut }}$ was significantly higher than that $(54 \%, 13 / 24)$ in patients who were negative for all of Exon $1^{\text {mut }}$, GPI ${ }^{-}$cells, and $6 \mathrm{pLOH}(P=0.023)$.

\section{Discussion}

Targeted deep sequencing of HLA genes of leukocytes obtained from AA patients with HLA-LL revealed a unique nonsense mutation at codon 19 (c.19C>T, p.R7X) in exon 1 (Exon $^{m u t}$ ) of different HLA-A and HLA-B alleles. This mutation has been previously reported in Japanese and American AA patients, but did not draw attention because the mutation was detectable in only a limited number of patients. ${ }^{9,14}$ Our highly sensitive ddPCR assay enabled the detection of minor Exon $1^{\text {mut }}$ clones and detected the mutant DNA in nearly one third of Japanese AA patients regardless of the presence of $6 \mathrm{pLOH}$. Exon $1^{\text {mut }}$ was also detected in two of eight Finnish AA patients we stud- ied (unpublished observation). Interestingly, a frameshift mutation (c.19delC, p.R7Efs) was also identified at codon 19 of $H L A-B^{*} 54: 01$ in a patient (UPN 210) without Exon $1^{\text {mut }}$, suggesting that the codon 19 in exon 1 of $H L A-A$ and $H L A-B$ may be a specific position at which somatic mutations are likely to occur.

The loss of HLA from CD34 $4^{+}$cells due to Exon $1^{\text {mut }}$ was verified by phenotypic analysis of Exon $1^{\text {mut }}$-positive iPS cellHSPC that were derived from monocytes of an AA patient who had approximately $14 \%$ Exon ${ }^{\text {mut }}$-positive cells among the granulocyte population. ${ }^{17}$ Exon $1{ }^{\text {mut }}$ has also been detected in several squamous cell carcinomas, such as head and neck tumors, oral cancers, and anal cancers, in previous studies. ${ }^{22}$ ${ }^{25}$ The solid tumors that lost HLA class I expression due to Exon1 $1^{\text {mut }}$ were thought to have escaped T-cell attack and acquired a proliferative advantage. Taken together, these findings suggest that Exon $1^{\text {mut }}$ is a common mechanism by which HSPC lose HLA, allowing them to escape from the effects of cytotoxic T lymphocytes in AA patients.

A

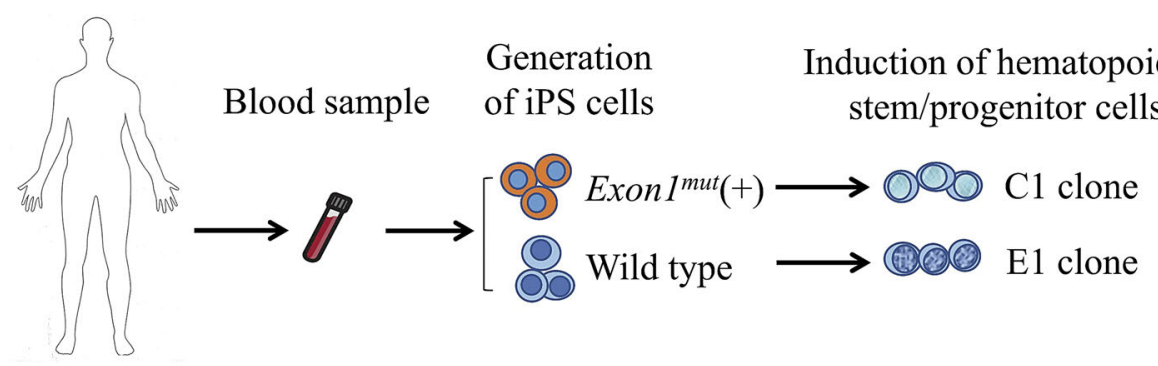

An AA patient

with Exon $1^{\text {mut }}$

(UPN 333)

B

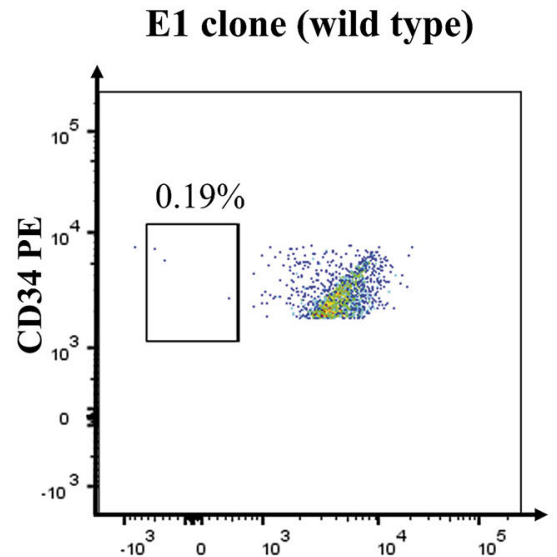

HLA-Bw6 (B5401) FITC

C

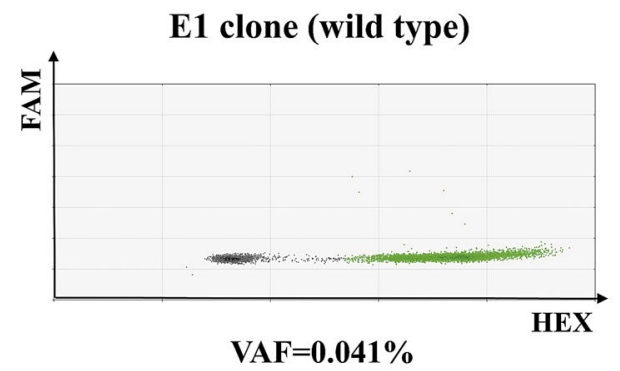

\section{C1 clone $\left(\operatorname{Exon}^{\mathrm{mut}}[+]\right)$}

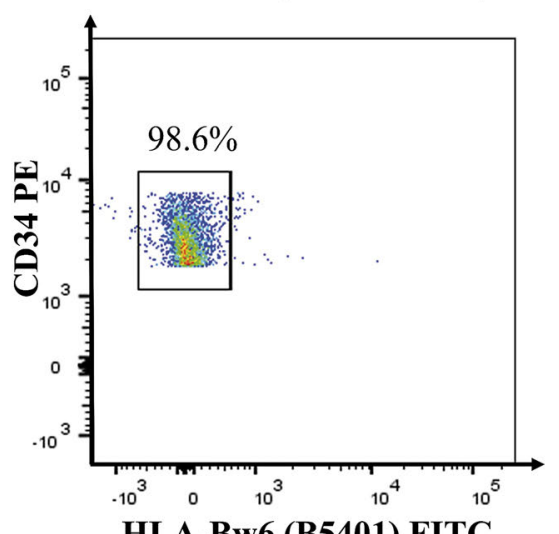

HLA-Bw6 (B5401) FITC

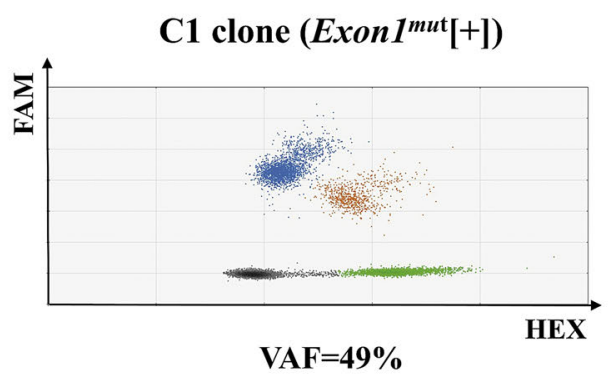

Figure 6. HLA allele expression by Exon $1^{\text {mut }}$ positive hematopoietic stem and progenitor cells. (A) Establishment of induced pluripotent stem cell (iPSC)-derived hematopoietic stem cells from monocytes of an aplastic anemia patient with Exon1 $1^{\text {mut }}$ (UPN 333). (B) HLA-Bw6 (B5401) expression by $\mathrm{CD} 34^{+}$cells derived from a wild-type iPSC clone (left) and an Exon $^{\text {mut }}$-positive iPSC clone (right). (C) Exon $1^{\text {mut }}$ detection in DNA from wild-type (left) and Exon $1^{\text {mut-positive (right) }}$ iPSC-derived CD34+ cells. Numbers below the scattergram denote the variant allele frequency of Exon 1 ${ }^{\text {mut }}$ AA: aplastic anemia; UPN: unique patient number; iPS cells: induced pluripotent stem cells; VAF: variant allele frequency. 
We previously used targeted deep sequencing to identify frequent loss-of-function mutations in three HLA class I alleles, $B^{*} 40: 02, A^{*} 02: 06$, and $B^{*} 54: 01.9,16,17$ The highly sensitive ddPCR assay described herein that was capable of detecting Exon $1^{\text {mut }}$ newly identified three HLA-A ( $A^{*} 02: 01$, $\left.A^{*} 02: 07, A^{*} 31: 01\right)$ and six HLA-B alleles $\left(B^{*} 13: 01, B^{*} 40: 01\right.$, $\left.B^{*} 40: 03, B^{*} 44: 03, B^{*} 55: 02, B^{*} 56: 01\right)$ as HLA alleles that are susceptible to allelic loss. Compared with their frequency in the general Japanese population, these HLA alleles were found to be highly enriched in AA patients. Among the 14 HLA class I supertypes that are defined based on similarities in the antigen-presenting peptide motif, the 12 alleles mentioned above belong to only four of the supertypes. ${ }^{21}$ These findings suggest that autoantigens of AA may be presented to $T$ cells by these specific HLA alleles on HSPC.

Like HSPC positive for $6 \mathrm{pLOH}$, those positive for Exon $1^{\text {mut }}$ are thought to escape the attack of cytotoxic $\mathrm{T}$ lymphocytes specific to autoantigens presented by the missing HLA-A or HLA-B allele and contribute to hematopoiesis over the long-term. However, it is unclear why Exon $1^{\text {mut }}$ occurs more frequently in HSPC than loss-offunction mutations in other positions of HLA class I alleles. Shukla et al. reported different hotspots of mutations in class I HLA genes according to cancer type, and identified Exon $1^{\text {mut }}$ only in head and neck squamous cell cancers. ${ }^{24}$ HSPC may thus share a common property in that Exon $1^{\text {mut }}$ is likely to occur in class I HLA genes in head and neck squamous cell cancers.

The median VAF of Exon1 ${ }^{\text {mut }}$ in patients with Exon1 $1^{\text {mut }}$ patients was only $0.42 \%$, a level that cannot be detected by targeted deep sequencing. This low VAF was in sharp contrast to the high proportion of concomitant $6 \mathrm{pLOH}$ in individual patients (Figure $3 \mathrm{C}$ ). We previously reported that $6 \mathrm{pLOH}^{+}$leukocytes were often polyclonal, consisting of leukocytes having different breakpoints of uniparental disomy in the short arm of chromosome $6 .{ }^{10}$ This polyclonality may account for the high proportion of $6 \mathrm{pLOH}$. Although the leukocytes with Exon $1^{\text {mut }}$ represent a minor leukocyte population, the long-term (1-7 years) persistence of these mutated leukocytes indicates that they are derived from HSPC with self-renewal capacity. Arends et al. showed that clone size of cells with somatic mutations of epigenetic regulation genes expanded from most immature hematopoietic stem cells to mature peripheral blood cells in patients with clonal hematopoiesis of indeterminate potential. ${ }^{26}$ Leukocyte positive for Exon $1^{\text {mut }}$ may also be derived from most immature hematopoietic stem cells. The persistence of similarly minor clones in peripheral blood has been reported for $\mathrm{GPI}^{-}$granulocytes in AA, the median frequency of which was $0.25 \%{ }^{18,27}$ In contrast to PIGA-mutated or $6 \mathrm{pLOH}^{+}$leukocytes, which can be oligoclonal and dysfunctional due to the lack of all GPIanchored proteins or a large segment of 6p, Exon $1^{\text {mut }}$-positive leukocytes are derived from a single HSPC that is phenotypically normal except for the lack of one HLA allele. According to Dingli's hypothesis, approximately 400 HSPC are actively involved in human hematopoiesis. ${ }^{28}$ Thus, the small proportion of Exon $1^{m u t}$-positive leukocytes among the entire leukocyte population may reflect an average clone size of individual HSPC in the bone marrow.

HLA-LL are useful markers that indicate the presence of an immune pathophysiology in patients with bone mar- row failure. Here we showed a high response rate to immunosuppressive therapy in patients with Exon $1^{\text {mut }}$, although patients without Exon1 ${ }^{\text {mut }}$ also had a high response rate likely due to the high prevalence of GPI cells. ${ }^{29-31}$ Several methods can be used to detect HLA-LL, including flow cytometry assays with monoclonal antibodies specific to HLA-A or HLA-B alleles, ddPCR or SNP arrays for detecting $6 \mathrm{pLOH}$, and targeted deep sequencing..$^{8-10,12}$ However, these methods require HLA typing of patients, take a long time to produce results, and are unable to detect HLA-LL that account for less than $1 \%$ of total leukocytes. The ddPCR assay used in the present study to detect Exon $1^{\text {mut }}$ enables the detection of HLA-LL accounting for as few as $0.07 \%$ of the total leukocyte population within $6 \mathrm{~h}$ of blood collection, highlighting the powerful nature of this assay for diagnosing immune pathophysiology in patients with bone marrow failure.

\section{Disclosures}

No conflicts of interest to disclose.

\section{Contributions}

$H M, T I, K T, Y Z$ and SN collected clinical data and blood samples. FA performed HLA genotyping. YF and SO conducted the SNP array analyses. YZ, HT, TO, HK and AM generated an original monoclonal antibody specific to $H L A-B 13, B 60$ and B61. HM and TY performed cell sorting. HM, KHosomichi, TI, $Y Z$ and AT performed deep sequencing. HM, YZ, NMA and TCD performed the droplet digital polymerase chain reaction. $K C$ and YY generated the induced pluripotent stem cells. MIE performed the in vitro experiments. HM, KHosokawa and SN designed the research and wrote the manuscript. All authors critically reviewed the manuscript and checked the final version.

\section{Acknowledgements}

The authors thank the patients and donors and their physicians, including M. Yamaguchi of Ishikawa Prefectural Central Hospital of Kanazawa, Ishikawa, T. Takaku of Juntendo University Hospital of Bunkyo-ku, Tokyo, H. Yano of Kainan Hospital of Yatomi, Aichi, K. Watamoto of Komaki City Hospital of Komaki, Aichi, M. Mizutani of Matsusaka Central General Hospital of Mastusaka, Mie, S. Morishima of University of Ryukyu Hospital of Nishihara, Okinawa, and Mikko Ker $\neg$ änen, Sofie Lun $\neg$ dᄀgren and Satu Mustjoki of the University of Helsinki, Helsinki, Finland for sending their patients' samples for screening for Exon1 mut, and the Advanced Preventive Medical Sciences Research Center, Kanazawa University for the use of facilities. HM is a PhD candidate at Kanazawa University and this work is submitted in partial fulfillment of the requirements for the $P h D$.

\section{Funding}

This work was supported by MEXT KAKENHI (Grant-inAid for Scientific Research [B], grant number: $16 \mathrm{H} 05335$ and 19H03686) to SN, MEXT KAKENHI (Grant-in-Aid for Young Scientists [B], grant number: 17K16184) to K.Hosokawa, MEXT KAKENHI (Grant-in-Aid for Scientific Research [C], grant number: 17K09007) to TK, MEXT KAKENHI (Grant-in-Aid for Scientific Research on Innovative Areas, grant number: $16 \mathrm{H} 06502$ and 19H05344) to K. Hosomichi., Hokuriku Bank Research Grant for Young Scientists to TK and Hokkoku Foundation for Cancer Research to TK and KHosokawa. 


\section{References}

1. Young NS. Aplastic anemia. N Engl J Med. 2018;379(17):1643-1656.

2.Zeng W, Nakao S, Takamatsu $\mathrm{H}$, et al. Characterization of T-cell repertoire of the bone marrow in immune-mediated aplastic anemia: evidence for the involvement of antigen-driven T-cell response in cyclosporine-dependent aplastic anemia. Blood. 1999;93(9):3008-3016.

3. Nakao S, Takami A, Takamatsu $\mathrm{H}$, et al. Isolation of a T-cell clone showing HLADRB1*0405-restricted cytotoxicity for hematopoietic cells in a patient with aplastic anemia. Blood. 1997;89(10):3691-3699.

4. Risitano AM, Maciejewski JP, Green S, et al. In-vivo dominant immune responses in aplastic anaemia: molecular tracking of putatively pathogenetic T-cell clones by TCR beta-CDR3 sequencing. Lancet. 2004;364(9431):355-364.

5. Wlodarski MW, Gondek LP, Nearman ZP, et al. Molecular strategies for detection and quantitation of clonal cytotoxic T-cell responses in aplastic anemia and myelodysplastic syndrome. Blood. 2006;108(8):26322641.

6. Inaguma Y, Akatsuka Y, Hosokawa K, et al. Induction of HLA-B*40:02-restricted T cells possessing cytotoxic and suppressive functions against haematopoietic progenitor cells from a patient with severe aplastic anaemia. Br J Haematol. 2016;172(1):131134.

7. Espinoza JL, Elbadry MI, Chonabayashi K, et al. Hematopoiesis by iPSC-derived hematopoietic stem cells of aplastic anemia that escape cytotoxic T-cell attack. Blood Adv. 2018;2(4):390-400

8. Maruyama H, Katagiri T, Kashiwase K, et al. Clinical significance and origin of leukocytes that lack HLA-A allele expression in patients with acquired aplastic anemia. Exp Hematol. 2016:44(10):931-939.e3.

9. Zaimoku Y, Takamatsu H, Hosomichi K, et al. Identification of an HLA class I allele closely involved in the autoantigen presentation in acquired aplastic anemia. Blood. 2017;129(21):2908-2916

10. Katagiri T, Sato-Otsubo A, Kashiwase K, et al. Frequent loss of HLA alleles associated with copy number-neutral $6 \mathrm{pLOH}$ in acquired aplastic anemia. Blood. 2011;118(25):6601-6609.

11. Yoshizato T, Dumitriu B, Hosokawa K, et al. Somatic mutations and clonal hematopoiesis in aplastic anemia. $\mathrm{N}$ Engl J Med. 2015;373(1):35-47.

12. Afable MG 2nd, Wlodarski M, Makishima $\mathrm{H}$, et al. SNP array-based karyotyping: differences and similarities between aplastic anemia and hypocellular myelodysplastic syndromes. Blood. 2011:117(25):6876-6884

13. Betensky M, Babushok D, Roth JJ, et al. Clonal evolution and clinical significance of copy number neutral loss of heterozygosity of chromosome arm $6 \mathrm{p}$ in acquired aplastic anemia. Cancer Genet. 2016;209(1-2):1-10.

14. Babushok DV, Duke JL, Xie HM, et al. Somatic HLA mutations expose the role of class I-mediated autoimmunity in aplastic anemia and its clonal complications. Blood Adv. 2017;1(22):1900-1910.

15. Montes P, Kerick M, Bernal M, et al. Genomic loss of HLA alleles may affect the clinical outcome in low-risk myelodysplastic syndrome patients. Oncotarget. 2018;9(97):36929-36944

16. Imi T, Katagiri T, Hosomichi K, et al. Sustained clonal hematopoiesis by HLAlacking hematopoietic stem cells without driver mutations in aplastic anemia. Blood Adv. 2018;2(9):1000-1012.

17. Elbadry MI, Mizumaki H, Hosokawa K, et al. Escape hematopoiesis by HLA-B5401lacking hematopoietic stem progenitor cells in men with acquired aplastic anemia. Haematologica. 2019;104(10):e447-e450.

18. Hosokawa K, Sugimori C, Ishiyama K, et al. Establishment of a flow cytometry assay for detecting paroxysmal nocturnal hemoglobinuria-type cells specific to patients with bone marrow failure. Ann Hematol. 2018:97(12):2289-2297.

19. MacConaill LE, Burns RT, Nag A, et al. Unique, dual-indexed sequencing adapters with UMIs effectively eliminate index crosstalk and significantly improve sensitivity of massively parallel sequencing. BMC Genomics. 2018:19(1):30

20. Kanda Y. Investigation of the freely available easy-to-use software 'EZR' for medical sta- tistics. Bone Marrow Transplant. 2013;48(3): $452-458$

21. Sidney J, Peters B, Frahm N, et al. HLA class I supertypes: a revised and updated classification. BMC Immunol. 2008:9:1

22. Pickering CR, Zhang J, Yoo SY, et al Integrative genomic characterization of oral squamous cell carcinoma identifies frequent somatic drivers. Cancer Discov. 2013;3(7): 770-781.

23. Mouw KW, Cleary JM, Reardon B, et al. Genomic evolution after chemoradiotherapy in anal squamous cell carcinoma. Clin Cancer Res. 2017;23(12):3214-3222.

24. Shukla SA, Rooney MS, Rajasagi M, et al. Comprehensive analysis of cancer-associated somatic mutations in class I HLA genes. Nat Biotechnol. 2015;33(11):1152-1158.

25. Li YY, Chung GT, Lui VW, et al. Exome and genome sequencing of nasopharynx cance identifies NF-kappaB pathway activating mutations. Nat Commun. 2017;8:14121.

26. Arends CM, Galan-Sousa J, Hoyer K, et al. Hematopoietic lineage distribution and evolutionary dynamics of clonal hematopoiesis. eukemia. 2018;32(9):1908-1919.

27. Sugimori C, Mochizuki K, Qi Z, et al. Origin and fate of blood cells deficient in glycosylphosphatidylinositol-anchored protein among patients with bone marrow failure. Br J Haematol. 2009;147(1):102-112.

28. Dingli D, Traulsen A, Pacheco JM. Compartmental architecture and dynamics of hematopoiesis. PLoS One. 2007;2(4): e345.

29. Sugimori C, Chuhjo T, Feng X, et al. Minor population of CD55-CD59- blood cells predicts response to immunosuppressive therapy and prognosis in patients with aplastic anemia. Blood. 2006;107(4):1308-1314.

30. Kulagin A, Lisukov I, Ivanova $M$, et al. Prognostic value of paroxysmal nocturnal haemoglobinuria clone presence in aplastic anaemia patients treated with combined mmunosuppression: results of two-centre prospective study. $\mathrm{Br} J$ Haematol. 2014;164(4):546-554

31. Narita A, Muramatsu H, Sekiya Y, et al. Paroxysmal nocturnal hemoglobinuria and telomere length predicts response to mmunosuppressive therapy in pediatric aplastic anemia. Haematologica. 2015;100 (12):1546-1552. 